\title{
ASSESSMENT AND MONITORING OF REHABILITATION STUDIES ON COAL MINE DUMP SITE WITH UAV'S
}

\author{
KUN, M. \\ Department of Mining Engineering, Faculty of Engineering, Dokuz Eylul University \\ Izmir, Turkey \\ (e-mail:mete.kun@deu.edu.tr; phone:+90-232-301-7540; fax:+90-232-453-0868)
}

(Received 25 ${ }^{\text {th }}$ Feb 2019; accepted $1^{\text {st }}$ May 2019)

\begin{abstract}
Today, the rapidly increasing environmental awareness and the need for available space posed environmentally sensitive change of mining activities and created the target of producing alternative economic values in the fields it is used. For this reason, especially for the last two decades, in the context of the rehabilitation and reactivation in the nature of open-cast mines whose production is either finisher or ongoing, nature restoration work after mining activities have gained momentum. In terms of country and regional planning studies, in the mining activities especially carried out in large areas, the rehabilitation of the sites in terms of the preservation and sustainability of the natural balance within the area is of great importance. With advanced technological equipment, remote sensing systems, unmanned aerial vehicles and increasing data processing techniques, it is possible to follow up the mining initiatives and rehabilitation works carried out especially in large areas. In this way, transaction tracking and success percentages of transactions can be revealed. In the study prepared for this purpose, a sample coal operation was taken into consideration and the rehabilitation works carried out especially at the dump sites were examined. As a result of the study, the adaptation of the species planted to the nature and the survival percent obtained were revealed. In addition to this, the rehabilitation processes on the dump sites were monitored with the help of plant index maps obtained by using unmanned aerial vehicle (UAV) and photogrammetric software and the success of applied methods was evaluated.
\end{abstract}

Keywords: mining, reclamation, plant index map, UAV, TGI, VARI

\section{Introduction}

Mines and mining are of great importance in continuation of today's modern lifestyle and achieving the goals set. Today, as in the past, mining is one of the largest industries. Some adverse effects on the environment are inevitable according to the methods followed during the running of a mine. When compared to underground mining, open pit mining has a more negative effect on the natural environment and the negative visual impact it creates is known to be greater than the underground mining.

The negative impacts of mining activities on the environment can be local and regional, as well as globally. These effects may vary slightly depending on the characteristics of the natural environment, the structure of the mine, the mining technique applied and the nature of the enterprise. Additionally, the realization, estimation, prevention or reduction of these environmental impacts caused by mining activities in real terms is possible with the measures to be taken during the planning of the activity.

Since mining is an activity that changes terrain surfaces, active mining activities in a given time period significantly change the landscape and tend to destroy all traces of land use in the past. The negative effects such as degradation of the visual environment, damage to the landscape, damage to agricultural and forest areas, erosion, land subsidence, etc. are focused on (Sengupta, 1993). However, the dump sites, which are formed in the immediate vicinity of the mine areas, are often larger than the active mining sites. The rehabilitation of these dump sites is a necessary and compulsory 
action (Malli. et al., 2018). For this reason, field rehabilitation practices were included in the operation procedure and costs, before starting the production, taking into account in the feasibility stages of their enterprises. Thus, when the mining works in the sites are completed, a large part of the sites become rehabilitated (Fig. 1).

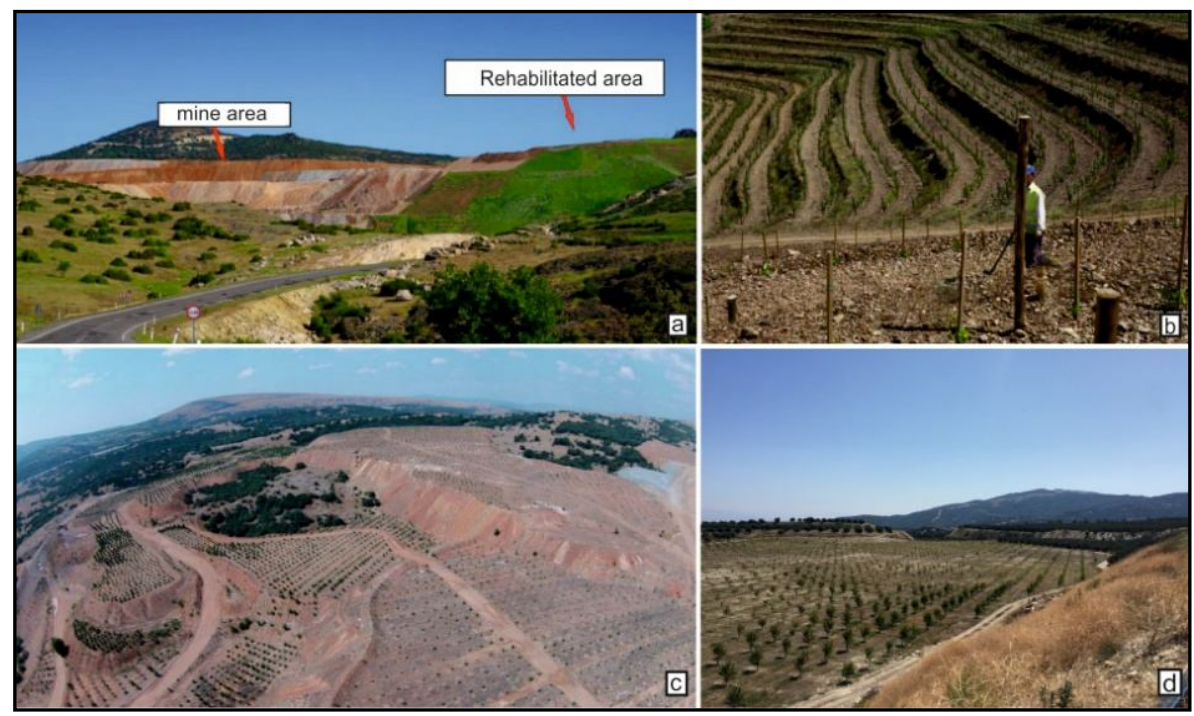

Figure 1. Rehabilitated mining sites [(a),(b) - Kısladag gold mine in Uşak/Turkey; (c)- Tutluca magnesite quary in Eskisehir/Turkey; (d)-coal mine rehabilitated area in Aydin/Turkey)]

Rehabilitation studies are generally divided into four stages by different researchers. These stages are classified as the site usage plan, reorganizing, improvement, monitoring and maintenance works (Topay and Kaya, 2007; Düzgün, 2009; Mallı et al., 2018). All of these steps were completed in the prepared study and especially as a result of the completed studies, the use of UAVs in the monitoring and research of tree planting sections were put forward.

Firstly planted areas were followed in five to seven year period and the results of planting studies in different fields were evaluated for this purpose. Secondly, the fields were visualized with UAV progress and the results were evaluated by using TGI and VARI values. As a result of the study, especially the planting of large areas, using UAVs and related visual processing software, according to the indexes given above as a result of the evaluation of plant life and long-term follow-up of the results obtained by classical means overlapped. This situation shows that the results of UAVs, 3D mining software, TGI and VARI values together can be performed accurately, reliably and fast, especially in the pursuit of the rehabilitation of large mining sites.

\section{Review of Literature}

Claim is the preparation of the mining operation area for post-mining use, and also the consolidation of the post-operational land by adapting to the environment (Ramani, 1990). In other words, it is defined as returning the area to its natural state or to a more suitable use, as bringing out the efficient, useful, clean and aesthetically beautiful appearance of the destroyed area (Michaud, 1981). The re-efficiency of a destroyed area and regaining its ecological, economic and aesthetic values is possible by the nature repair works. 
Site usage plan is defined as the formation of the conditions for the land and the determination of ecological targets for re-planting before mining. Reorganizing involves activities such as excavation, soil laying, planting, drainage works etc. The improvement phase is the studies of recovery of biological efficiency in the destroyed area and evaluation and improvement of the soil and the re-planting. The monitoring phase, which is the last stage, can be defined as the phase during which plant development is monitored and evaluated in line with the determined targets after the stages of organizing and improvement. In the study, these processes were done both by classical means and with the help of UAVs and the results were compared.

There are many studies that show the use of UAVs and their successful use in the fields of mining and the environmental relation. For example, Ozcan and Sari (2019) and Gül (2019), in their studies on the environmental effects and monitoring of quarries, respectively, have demonstrated the success of UAVs in open mines planning. Again, Lee and Choi (2016) focused on the safe use of UAVs for different purposes (planning and monitoring) in mining operations in a study called reviews of unmanned aerial vehicle (drone) technology trends and its applications in the mining industry. Shahbazi et al. (2014) the management, monitoring and management of natural resources unmanned aerial imagery has clearly demonstrated the latest developments and achievements. Özcan (2017) and Öztürk et al. (2017), the effects of the images taken with different elevation and camera angles, respectively, were investigated and the differences between the steep and sloping image acquisition from mining sites were determined.

There can be found several other examples in the literature that have assessed suitability of mined lands for post-mining land-uses, and mentioned the effective criteria in the evaluations. For expample, Maiti and Ghose (2005); Tafi (2006) and Carrick and Kruger (2007) have evaluated the factors limiting plant growth on mined soils and mentioned the most serious soil limitations. Some other researchers e.g. Gizikoff (2004) and Zavadskas and Antucheviciene (2006) have investigated on so many other factors such as topography, climate, environment, society, economy, etc. which arise in land-use evaluations of mined or other disturbed lands. Paschke et al. (2003); Meech et al. (2006); Li (2006) and Cao (2007) have focused on special postmining land-uses thatwere exercised in some mine sites.

Moreover, extensive studies are carried out in different parts of the world. For example, the value of claim costs in the US West Kentucky basin was estimated to be around $8 \%$ of the total operating cost. In another study, it was determined that the cover/coal ratio was 8:1 and for each 100 tons production, 0.2 hectares of land was damaged; the cost of claim in an open pit mine was determined to be $\$ 0.32 /$ ton or $7.6 \%$ of the total cost. In the literature, this value varies between $\$ 1000$ and $\$ 20000$ per hectare. In addition, with the project of East Germany rehabilitation of lignite mines, more than 100 thousand hectares of land became usable and was regained to the environment by spending 7.5 billion euros (Kuyumcu, 2005).

As seen in the above-mentioned similar studies, the necessity of rehabilitation of the sites as well as the need to regain economic values from the mining areas, encourages enterprises in this direction. Therefore, in the following parts of the study, the rehabilitation studies carried out in the new and old dump sites of the coal mine discussed and follow-up and monitoring of these studies with today's technologies were mentioned. 


\section{Materials and Methods}

\section{Description of the study area}

Lignite production site discussed in the study is located in western Turkey, on the Aegean Coast, in the province of Aydin. Until the year 1984 the production was only underground and since 84 to the present day it has functioned as both underground and open-pit production. Until today, about 7 million tons of coal were produced from underground mine and 10 million tons of coal were produced from the open pit mine. In the production process, approximately 160 million $\mathrm{m}^{3}$ of excavation was carried out on the open pit mine. Fig. 2 shows the site location map, the study area and the rehabilitation areas belonging to the lignite pit.

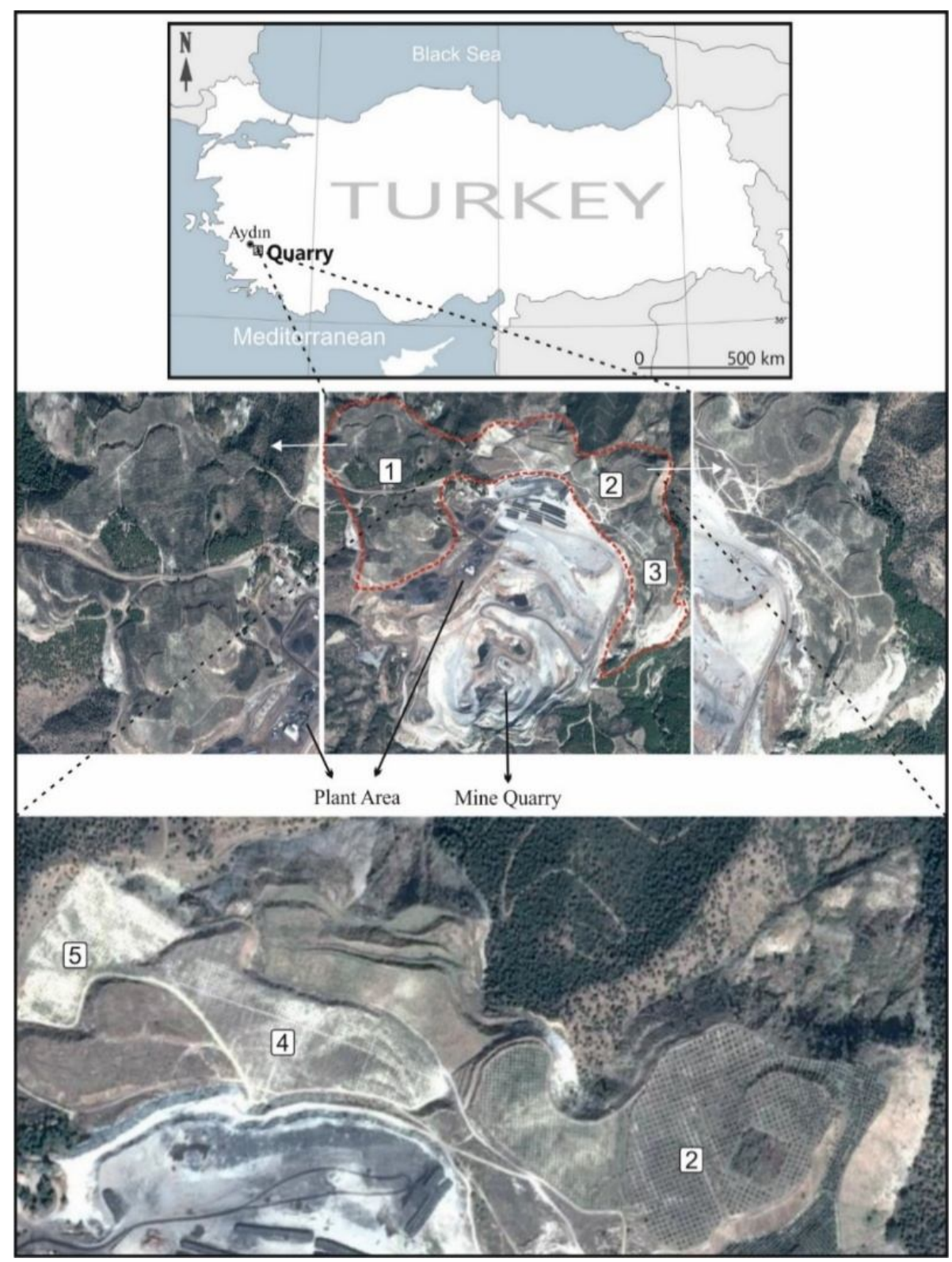

Figure 2. Open pit mine quaryy and dump sites (number 1-5 and area coordinates: between longitudes $27^{\circ} 56^{\prime} 12.80^{\prime \prime}$ E to $27^{\circ} 55^{\prime} 44.25^{\prime \prime}$ E and latitudes $37^{\circ} 46^{\prime} 47.86^{\prime \prime} \mathrm{N}$ to $37^{\circ} 46^{\prime}$ $\left.32.87^{\prime \prime} N\right)$. 


\section{Data collection}

\section{Planting studies and applications in the field}

Field studies are listed as the determination of the species that are available before the mining operation, establishment of research zones on the damaged areas and the casting areas, conducting the soil analysis of the areas, sapling planting in the areas formed and maintenance and monitoring of the planted areas.

According to this, the active species in the vicinity of the mine and in the region were determined. Most active tree species in the region are; Pinus Brutia Ten, Rolium Olivarum, Robinia Pseudoacacia and Amygdolus Communis. These identified species were planted in the experimental areas determined on the casting areas whose analysis are given in Table 1. Soil analyzes in the determined planting areas were made every 6 months starting 1 year before planting, and every $50 \times 100$ meters. The average values of these soil analyzes in Table 1 are given. In addition, the planting process has been completed with a 5 x 5 meter square and a 20-25 square meter seedling has been completed.

Table 1. The characteristics of soil used in plantation

\begin{tabular}{c|c|c}
\hline Parameters & Unit & \\
\hline Sand & $\%$ & $54.5 \pm 2.5$ \\
Dust & $\%$ & $38.56 \pm 2.11$ \\
Clay & $\%$ & $6.88 \pm 1.2$ \\
$\mathrm{CaCO}_{3}$ & $\%$ & $9.98 \pm 2$ \\
$\mathrm{pH}$ & - & $6.92 \pm 1.2$ \\
Organic Subs. & $\%$ & $2.55 \pm 0.7$ \\
$\mathrm{~N}$ & $\mathrm{mg} \mathrm{kg}^{-1}$ & $0.008 \pm 0.001$ \\
$\mathrm{P}$ & $\mathrm{mg} \mathrm{kg}^{-1}$ & $3.0 \pm 0.5$ \\
$\mathrm{~K}$ & $\mathrm{mg} \mathrm{kg}^{-1}$ & $156 \pm 12$ \\
$\mathrm{Ca}$ & $\mathrm{mg} \mathrm{kg}^{-1}$ & $2700 \pm 22$ \\
$\mathrm{Na}$ & $\mathrm{mg} \mathrm{kg}^{-1}$ & $75 \pm 8$ \\
$\mathrm{~B}$ & & $3.22 \pm 1.03$ \\
\hline
\end{tabular}

*The samples were taken from 30/50 centimeter depth

The evaluation of the seven years data for Rolium Olivarum and also two years data for Amygdolus Communis obtained from this phase were made by evaluating min 1000 saplings and the data were interpreted statistically. As a result of the evaluations, there were differences in terms of survival percent among the species mentioned above. According to this; about $99 \%$ of Rolium Olivarum, about $94 \%$ of Robinia Pseudoacacia, 82\% of Amygdolus Communis and about \% 77 of Pinus Brutia Ten survived in the dump sites (Table 2). These values were obtained for Rolium Olivarum eight years later and for Amygdalus Communis two years after planting.

Table 2. Survival statistics of several tree species on dump sites (\%)

\begin{tabular}{c|c}
\hline Tree Specie & Chance of Survival (\%) \\
\hline Rolium Olivarum & 99 \\
Robinia Pseudoacacia & 94 \\
Amygdolus Communis & 80 \\
Pinus Brutia Ten & 77 \\
\hline
\end{tabular}


Considering the high survival percent of Rolium Olivarum; both because it would increase the success in the rehabilitation process and in order to commercially evaluate the crop obtained from Rolium Olivarum planting, areas numbered 1,2,3 in the casting areas shown in Fig. 2 were totally planted Olivarum trees. The casting sites where Rolium Olivarum are planted in a geometry of $5 \mathrm{~m}$ x $5 \mathrm{~m}$ and crop today ( $20 \mathrm{~kg}$ oil/tree) are given in Fig. 3.

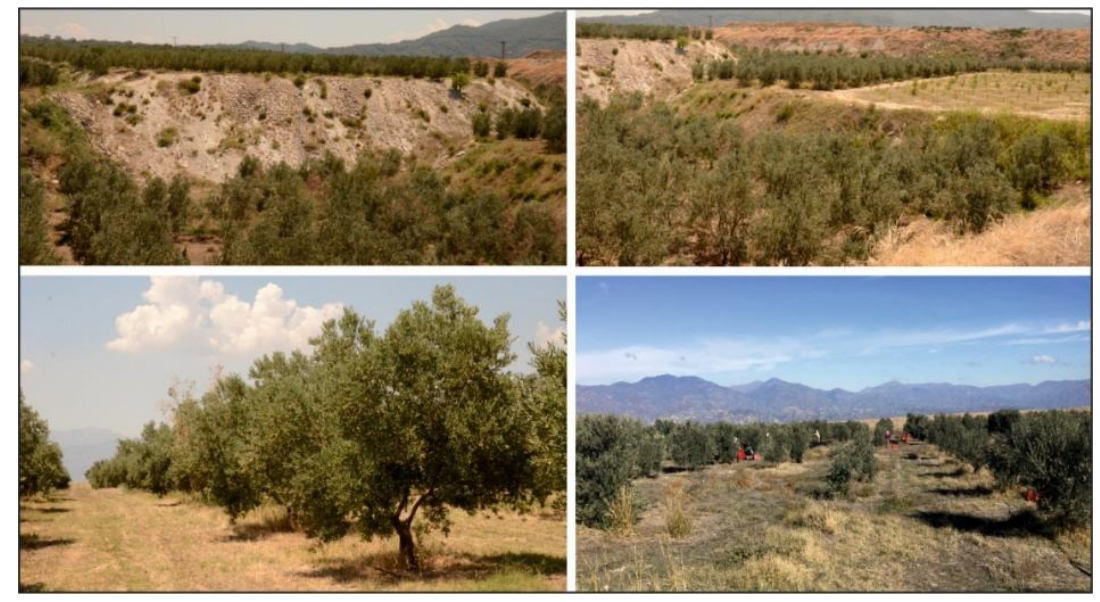

Figure 3. Planting dump sites (Rolium Olivarum)

Because of the factors such as the spreading of open pit casting sites to a very large area, the presence of Amygdolus Communis with Rolium Olivarum among the primary tree species in the region, ensuring diversity in the areas to be planted, and economic yield obtained from the crop of Amygdolus Communis trees, areas numbered 4 and 5 shown in Fig. 2 were planned to plant Amygdolus Communis. For this reason, samples were taken from $30 / 50 \mathrm{~cm}$ from the casting sites corresponding to the regions numbered 4 and 5 in the site and the soil properties given in Table 3 were obtained. Soil samples were taken for each 50 x 100 meter square area. The planting of 1750 Amygdolus Communis trees in the area of approximately 70 hectares numbered 5 and 6 in Fig. 2 and their current situation are shown in Fig. 4. About 2 years old trees were planted in $5 \times 5$ geometry. Watering the trees is done by drip irrigation as in olive.

In addition to this, the fertilization process done when necessary (rarely applied) also yielded positive results. As a result of research, the main element of the success in the afforestation was determined as the suitability of the characteristics of the soil (casting material) to be planted to the rapid root development. The plants tested in the field can be evaluated in the selection of species in the afforestation of different fields unless there is another restriction giving positive results in the expected direction. However, when afforestation is done with mixed tree species, planting in groups should be preferred by taking different biology of species into consideration (fast growing tree species are light trees). It is also advised to fertilize with organic fertilizers where possible and to irrigate especially in the first two years. Due to the facts that it has the highest survival percent in the area of re-cultivation and will provide economic contribution in terms of mine's economy in the future, approximately 50,000 olive saplings were planted. As a result of the investigations carried out in this area, it was determined that about $20 \mathrm{~kg}$ of crop per tree is obtained from these saplings and approximately 1000 tons of olives are produced annually. 
Table 3. The characteristics of soil used in Amygdolus Communis

\begin{tabular}{c|c|c}
\hline Parameters & Unit & \\
\hline $\mathrm{Salt}$ & $(\mu \mathrm{S} / \mathrm{cm})$ & 418 \\
$\mathrm{CaCO}_{3}$ & $\%$ & 7.83 \\
$\mathrm{pH}$ & - & 7.8 \\
Organic Subs. & $\%$ & 1.08 \\
$\mathrm{~N}$ & $\%$ & - \\
$\mathrm{P}$ & $\mathrm{ppm}$ & 0.50 \\
$\mathrm{~K}$ & $\mathrm{ppm}$ & 110 \\
$\mathrm{Ca}$ & $\mathrm{ppm}$ & 5134 \\
$\mathrm{Mg}$ & $\mathrm{ppm}$ & 226 \\
$\mathrm{Cu}$ & $\mathrm{ppm}$ & 0.36 \\
$\mathrm{Fe}$ & $\mathrm{ppm}$ & 4.27 \\
$\mathrm{Mn}$ & $\mathrm{ppm}$ & 3.24 \\
$\mathrm{Zn}$ & $\mathrm{ppm}$ & 0.68 \\
$\mathrm{~B}$ & $\mathrm{ppm}$ & 0.32 \\
\hline
\end{tabular}

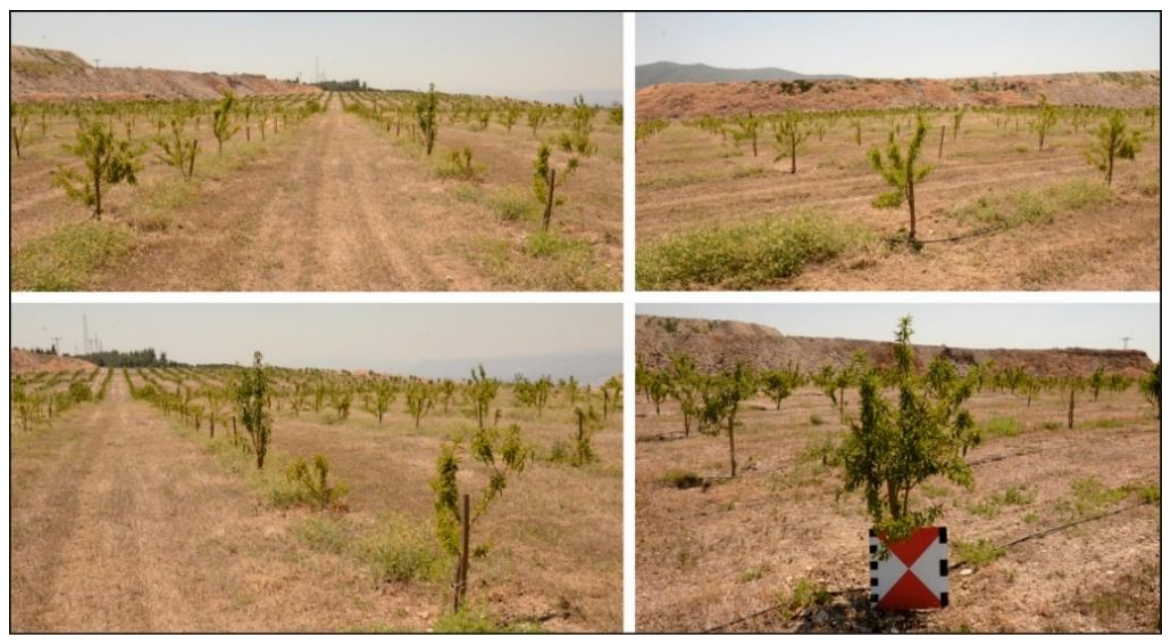

Figure 4. Planting dump sites (Amygdolus Communis)

\section{UAV data's and technical parameters}

UAV used in the acquisition of images has 1 inch 20 MP CMOS sensor and $35 \mathrm{~mm}$ focal length, with a single piece lens also the device can take $5472 \times 3648$ pixel resolution in JPG and RAW format image. In addition, it has GLONASS and GPS satellite support positioning module, $10 \mathrm{~m} / \mathrm{s}$ wind resistance, $7 \mathrm{~km}$ horizontal, $500 \mathrm{~m}$ vertical control control distance, $0-40^{\circ} \mathrm{C}$ temperature range, between 2.4 and $5.8 \mathrm{Ghz}$ frequency channels in case of need can make the transition.

In addition to the UAV used in the study, the Ashtech Promark 800 GNSS device was used as the positioning system. Real time positioning most accurate tolerance are $10 \mathrm{~mm}$ $\pm 1.0 \mathrm{ppm}$ in horizontally and $20 \mathrm{~mm} \pm 1.0 \mathrm{ppm}$ in vertically. The system is able to deliver real-time raw data and location output up to $20 \mathrm{~Hz}$. Also, unmanned aerial system flight parameters are clearly shown in Table 4. 
Table 4. Unmanned Aerial Vehicle Flight Parameters

\begin{tabular}{c|c}
\hline Flight parameters & Values \\
\hline Flight altitude & 70 meters \\
Flight velocity & 32 kilometers per hour \\
Flight overlap (Side - Front) & $\% 70-\% 70$ \\
Area covered & 0.401 square kilometers \\
Image amount & 303 images \\
Average ground sampling distance & 2.84 centimeters \\
\hline
\end{tabular}

\section{Research methodology}

Unmanned aerial vehicles and photogrammetric software, which are used in many different branches of industry, are used effectively in mining industry especially in planning and rehabilitation studies. The facts that the rehabilitation areas are quite large and difficult to access from time to time, and that the measurements and determinations are made in a short time and they are repeatable allowed the UAVs to be included in these areas. With the UAV, "plant index maps" of the fields can be obtained and the health status of the areas that are brought back to the nature can be determined and controlled.

In the field of especially newly planted Amygdolus Communis (Fig. 2, field numbered 4) and olive fields in close vicinity (Fig. 2, field numbered 2) shown in Fig. 4, flights were made on the dump sites to reveal the rehabilitation model of the site. The flight plans for the flights are given in Fig. $5 a$. In total 313 visual reception fields, four aboveground control points were used for the purpose of controlling the system. In the study which especially focused on the new planting areas where Amygdolus Communis trees are located and the vicinity, an area of approximately five hectares was investigated in the first place. The position of the UAV on the site numbered 4 (Amygdolus Communis tree planting area) is shown in Fig. $5 b$ as an example.

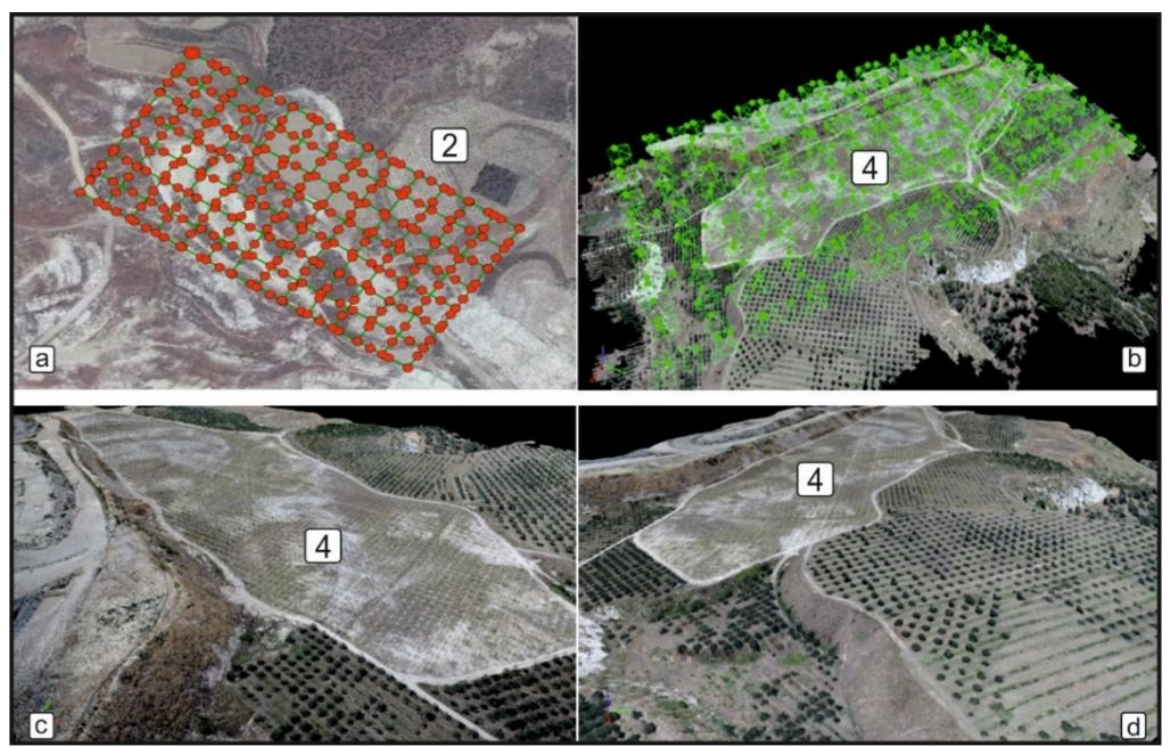

Figure 5. UAV datas on dump sites [(a) UAV fligth plan; (b) UAV position on Amygdolus Communis plant area; (c) and (d) solid models] 
High-resolution images of the planted area were processed using pix $4 \mathrm{D}$ software, and a cloud of approximately 10 million 735 thousand points was obtained from the entire area with a mean error margin of less than $4 \mathrm{~cm}$ in the measurement. Fig. $5 d$ shows the solid model of the sites produced from the point cloud.

"Vegetation index maps" were obtained by processing of received images. The purpose here is to determine the health status of the plants in the field studied and to follow the development process. Since the study was done with a UAV with integrated RGB camera, TGI (Triangular Greenness Index) and VARI (Visible Atmospheric Resistant Index) indices were used together as vegetation index. The TGI and VARI indices were preferred because of the facts that they stand out among other visual indexes and especially that the VARI index can be used in all stages of plant life (Hunt et al., 2011).

TGI index, the reflected spectrum value from the plant; is the junction area of the triangle that ground on blue $(480 \mathrm{~nm})$, green $(550 \mathrm{~nm})$ and red $(670 \mathrm{~nm})$ spectral values as the corner point (Fig. 6). The TGI index value (green reflection value) is has a positive value if it is above the line combining $480 \mathrm{~nm}$ and $670 \mathrm{~nm}$ values; and if not it has a negative value. While the positive value (green color) indicates healthy vegetation, the negative value (red color) indicates soil cover (Hunt et al., 2011).

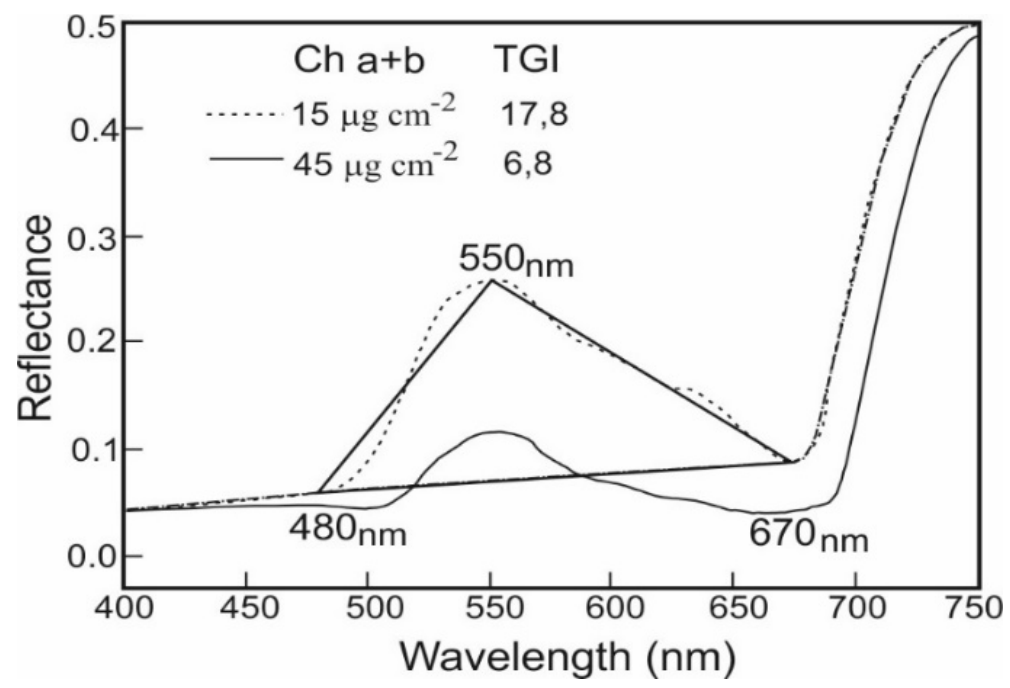

Figure 6. TGI indeks (Reflected spectrum value from the plant)

Red, green and blue colors contain information throughout the growing season. The VARI index is determined by the transitions of the green's reflection value with the red edges. VARI is designed to provide an atmospheric correction and is a good and valid index to predict the vegetation fraction from the visible range of the spectrum. This index can be used to analyze plants in all growth stages (Gitelson et al., 2002).

The VARI and TGI index maps and index value distributions divided into four parts of the rehabilitation area studied are visualized as histograms in Fig. 7 and Fig. 8.

Because newly planted almond seedlings are considered first, TGI index was used as subsidiary index by basing on the VARI index applicable to all stages of plant life. The range of values for the VARI index: Value ranges changing between "-1"and " 1 " that are frequently used in field work are used. In Table 5, VARI index values and their meanings are given. 


\section{Results}

Within the scope of the study, the close geography of the site was examined and the experimental plantings for olive and almond trees, which were determined as a priority, were observed and examined between two and seven years. When the experimental plantings in the casting areas yielded positive results by $99 \%$ in Rolium Olivarum and by $80-82 \%$ in Amygdolus Communis, the sites were mainly afforested with these two species. 50.000 olive saplings were planted in a large part of the dump sites, which has the highest percentage of survival, and which will provide economic contribution in terms of business economy. Today, an average of $20 \mathrm{~kg}$ crop per tree is obtained from these planted sites and approximately 1000 tons of olives are produced annually. In other dump sites, to increase plant diversity and produce economic return, Amygdolus Communis were planted in almost 70 hectares and they were monitored.

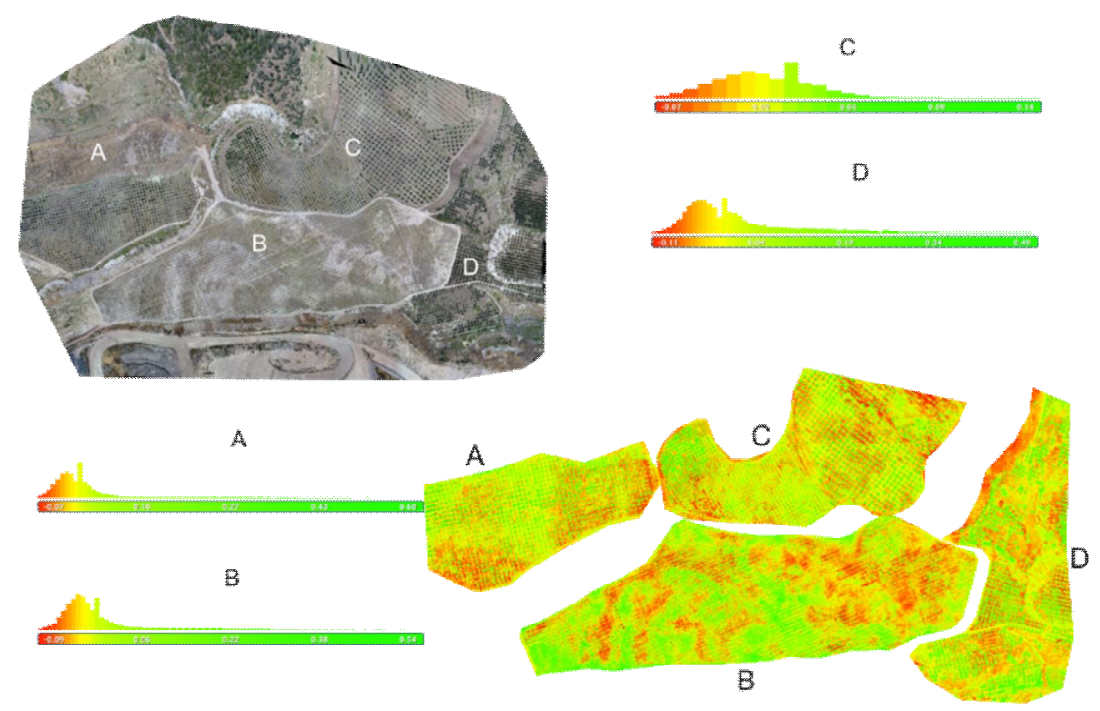

Figure 7. Visible atmospherically resistant indeks (VARI) of planting dump sites

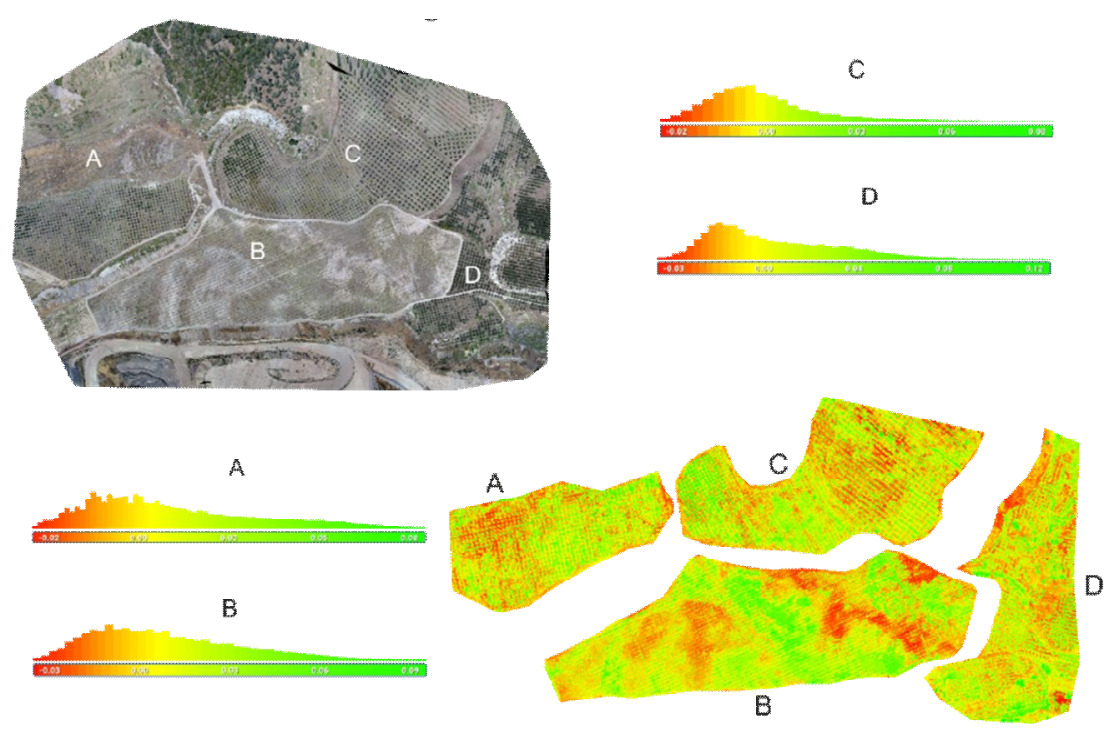

Figure 8. Triangular greenness indeks (TGI) of dump sites planting dump sites 
Table 5. VARI Index value range and meanings

\begin{tabular}{c|c}
\hline VARI index value & Meanings \\
\hline$<0$ & Lifeless or dead plant \\
$0-0.33$ & Immature plant \\
$0.33-0.66$ & Healty plant \\
$>0.66$ & Very healthy plant \\
\hline
\end{tabular}

"Plant index maps" were prepared in the site in order to follow and evaluate the plantation and afforestation processes, which is another stage of the study, with UAVs (Fig. 7 and Fig. 8). According to the obtained plant index maps, when the VARI index values are examined in parallel with the high survival percent of Rolium Olivarum both in the experimental areas and in the site, it was determined that it the ones in the range of 0.33 and 0.66 are in the class of "Healthy Plant". This value indicates the class of "immature plant". Additionally, with the UAVs, the visualization of the sites and the processing of the obtained point clouds and the success of the planting process in the site were followed by color scales. Similarly, the intense green color (90-92\%) observed in the olive tree region demonstrates the success of the application and monitoring technique. This ratio was obtained between $75-80 \%$ in Amygdolus Communis planting area.

\section{Discussions}

In the present study, a sample study was conducted in order to rehabilitate the heaps of dump sites formed by pickling materials in open coal pits and to monitor the rehabilitated sites. The purpose of the rehabilitation site while mining activities continue was determined as to ensure nature restoration after mining activities by re-creating natural vegetation of the site before mining activities and to generate economic income by planting in these fields.

In this context, the field studies conducted with the help of long-term field studies and the UAVs can be used actively in monitoring the plants and determining the faces of life. Furthermore, with the help of the UAVs, the removal of plant index maps in the course of the restoration of large mining sites has been shown to be a fast, reliable and modern method to control the success of the rehabilitation processes at the sites.

Acknowledgements. The author would like to thank Dokuz Eylul University Department of Scientific Research Projects for the support of 2017.KBFEN.021. Also, the author would like to thank Mining Engineer Ahmet Ozer of Aydın Lignite Enterprises and Yücel Açıkgöz and Ali Ince from the Agriculture Department of the same corporation.

\section{REFERENCES}

[1] Cao, X. (2007): Regulating mine land reclamation in developing countries: the case of China. - Land Use Policy 24: 472-483.

[2] Carrick, P. J., Kruger, R. (2007): Restoring degraded landscapes in lowland Namaqualand: Lessons from the mining experience and from regional ecological dynamics. - Journal of Arid Environments 32: 52-67. 
[3] Düzgün, Ş. (2009): The basic principles of restoration and mine closure. - In: Chamber of Mining Engineers of Turkey: 3th International Symposium on Mining And Environment, Ankara, June 11-12, 2009: 1-4.

[4] Gitelson, A., Kaufman, Y., Stark, R., Rundquist, D. (2002): Novel algorithms for remote estimation of vegetation fraction. - Remote Sensing of Environment 80: 76-87.

[5] Gizikoff, K. G. (2004): Re-Establishing livestock use on mined landscapes in the southern interior of BC. - In: UBC: Proceedings In: Annual British Columbia Mine Reclamation in Campbell River, BC, June 20-31, 2009: 1-11.

[6] Gül, Y. (2019): Applications of Unmanned Aerial vehicle (UAV) in open-pit mines. Geological Bulletin of Turkey 62: 99-112.

[7] Hunt, J. E., Daughtry, C., Eitel, J. U., Long, D. (2011): Remote sensing leaf chlorophyll content using a visible band index. - Agronomy Journal 103: 1090-1099.

[8] Kuyumcu, M. (2005): The rehabilitation and integration of lignite mines in Western Germany. - In: Chamber of Mining Engineers of Turkey: International Symposium on Mining and Environment, Ankara, June 11-12, 2005: 165-172.

[9] Lee, S., Choi, Y. (2016): Reviews of unmanned aerial vehicle (drone) technology trends and its applications in the mining industry. - Geosystem Engineering 9(4): 197-204.

[10] Li, M. S. (2006): Ecological restoration of mineland with particular reference to the metalliferous mine wasteland in China: a review of research and practice. - Science of the Total Environment 357: 38-53.

[11] Maiti, S. K., Ghose, M. K. (2005): Ecological restoration of acidic coalmine overburden dumps - an Indian case study. - Journal of Land Contamination and Reclamation 13: 361370.

[12] Mall1, T., Kun, M., Tufan, B. (2018): The technical and economic evaluation of reclamation studies in open pit mining. - Environmental Engineering and Management Journal 17: 11-18.

[13] Meech, J. A., McPhie, M., Clausen, K., Simpson, Y., Lang, B., Campbell, E., Johnstone, S., Condon, P. (2006): Transformation of a derelict mine site into a sustainable community: the Britannia project. - Journal of Cleaner Production 14: 349-365.

[14] Michaud, L. H. (1981): A manual of reclamation practice. - International Academic Services Ltd.

[15] Ozcan, O., Sari, H. (2019): Determining the spatial effects of quarries using a drone: the case of the Suleymanpasa-Tekirdag quarries. - Fresenius Envitonmental Bulletin 28(1): 53-61.

[16] Özcan, O. (2017): Accuracy assessment of the digital surface models (DSMs) generated from different altitudes using unmanned aerial vehicle. - Journal of Engineering and Earth Science 1: 1-7.

[17] Öztürk, O., Bilgilioğlu, B. B., Çelik, F., Bilbilioğlu, S. S., Uluğ, R. (2017): The investigation of the height and the camera angle in the production of orthoimage with Images of unmanned aerial vehicle (UAV). - Journal of Geomatics 2(3): 135-141.

[18] Paschke, M. W., Redente, E. F., Brown, S. L. (2003): Biology and establishment of mountain shrubs on mining disturbances in the rocky mountains. - Land Degradation and Development 14: 459-480.

[19] Ramani, R. V., Sweigard, R. J., Clar, M. L. (1990): Reclamation Planning-surface Mining Handbook. - SME: 750-769.

[20] Sengupta, M. (1993): Environmental Impacts of Mining: Monitoring Restoration, and Control. - Lewis Publisher.

[21] Shahbazi, M., Théau, J., Ménard, P. (2014): Recent applications of unmanned aerial imagery in natural resource management. - GIScience \& Remote Sensing 51: 339-365.

[22] Tafi, T. C. (2006): Reclamation effectiveness at three reclaimed abandoned mine sites in Jefferson County, Montana. - MsC Thesis, Montana State University, Bozeman, Montana. 
[23] Topay, M., Kaya, L. G. (2007): The education of landscaping in Turkey. - 3rd Landscape Architecture Congress, Antalya, Turkey, 554-557.

[24] Zavadskas, K. E., Antucheviciene, J. (2006): Development of an indicator model and ranking of sustainable revitalization alternatives of derelict property: a Lithuanian case study. - Sustainable Development 14: 287-299. 